\title{
Chondromyxoid Fibroma of Great Toe: A Unique Case Report
}

\author{
S.Tontanahal T.D.Bhattacharyya, S.Mittal R.Ailani, A.Gaikwad \\ Gauhati Medical College, Guwahati, Assam
}

\begin{abstract}
Chondromyxoid fibroma (CMF) is a rare bone tumour; classically occurring in the metaphyseal region of the long bones surrounding the knee. The small bones of the feet are also commonly involved. We report a case of Chondromyxoid fibroma of the proximal phalynx of the left great toe in a 25 year old male. The radiological appearance of a trabeculated lytic lesion with sclerotic margins raised the possibility of various other lesions including infections. However the typical microscopic picture of lobules of cartilage separated by fibrocellular tissue and scattered osteoclasts confirmed the diagnosis. This tumour was successfully treated with curettage and corticocancellous bone graft from iliac crest given via a dorsal incision and had no recurrence at 2 year follow up. In this article we present our experience with this case.
\end{abstract}

\section{- Introduction}

Chondromyxoid fibroma, a concept suggested by Jaffe and Lichenstein (1), is a rare primary skeletal tumour accounting for less than $0.5 \%$ of all bone tumours $(2,3)$. It occurs frequently around the knee, and the small bones of the foot are the second most common site. In the foot it most commonly involves the tarsals or the metatarsals, while involvement of the phalanges is rare.

\section{- Case Report}

A 25 year old male student presented with a swelling of the great toe which was more prominent on the dorsal surface. The swelling was ovoid in shape and extended from the metacarpophalangeal joint to the middle of the toe. It was gradually progressive over a period of 5 years and on presentation the size was $5 \mathrm{~cm} \mathrm{X} 4 \mathrm{~cm}$ with a hard consistency. The swelling was not associated with pain. The range of motion of the interphalangeal joint was restricted. Radiological examination revealed a lobulated osteolytic lesion with cortical thinning and sclerosis. An open biopsy was subsequently performed and reported to be a benign cartilaginous tumour.

Through a single dorsal incision over the great toe, the tumour was identified and thoroughly curetted through a window made on the dorsal aspect of the phalynx while preserving the articular surfaces of the bone. A corticocancellous bone graft from iliac crest was given in the formed cavity and was fixed in position with a Kirschner wire placed till the metatarsal.

Histological examination revealed a classical lobulated cartilage separated by fibrocellular tissue. Stellate cells and spindle cells were found scattered in the tumour. Osteoclast like cells were found at the interface between these tissues. There was no histological evidence of malignancy.

At 4 months of follow up there is good integration of the grafted bone and no evidence of recurrence of the tumour according to subjective symptom and radiographs.

\section{- Discussion}

Chondromyxoid fibroma is a rare neoplasm of bone which is derived from skeletal connective tissue cells which demonstrate the capacity to produce chondro-myxoid matrix in a distinctive histological pattern. The most common bones affected are those of the lower extremities and in only $5 \%$ of cases are the toes involved (3).

CMF is usually metaphyseal and eccentrically located in long bones and has well-defined sclerotic margins on radiological evaluation. In the small bones lesions are osteolytic with scalloped margins, an appearance which overlaps with Non-Ossifying Fibroma. The lesion occupies the entire width of the bone with expansion or erosion of the overlying cortex. Calcification within the lesion is visible in most cases $(4,5)$.

The preoperative radiological diagnoses include enchondroma, aneurysmal bone cyst, osteomyelitis, chondroblastoma, giant cell tumour and so on (6). Intra-medullary tumours and tumour-like lesions of the toe phalanges are rare. Among benign lesions enchondroma is probably the most common and may be clinically and radiologically indistinguishable from CMF (7).

The diagnosis can usually be made by biopsy. CMF is mostly myxoid and often has osteoclastic giant cells whereas enchondroma is cartilaginous and lacks giant cells. However a small biopsy may not have enough tissue for this distinction. Other benign tumours or tumour-like lesions which may rarely occur in the toes include aneurysmal bone cyst, the closely related giant cell reparative granuloma, and true giant cell tumour all of which are histologically quite different from CMF (7). 
The age of the patient is a predictor of recurrence rates. The thin cortex and the spongiosa of children's bones have a lower resistence and hence the tumour is more aggressive (8). High recurrence rate is also asocciated with inappropriate surgical management. Curettage alone has given poor reults however results improve with addition of bone graft (9). A chondromyxoid fibroma of the proximal phalynx of the great toe is of special interest due to its unusual location and peculiar toe preserving treatment method.

\section{References}

- Jaffe H., Lichenstein L: Chondromyxoid fibroma of a bone, a distinctive benign tumour likely to be mistaken especially for chondrosarcoma. Arch Path, 45: 541 - 545, 1948.

- $\quad$ Fletcher CDM, Unni KK, Mertens F (eds): Pathology and Genetics of Tumours of Soft Tissue and Bone, WHO Classification of Tumours, IARC Press, Lyon: $243-245,2002$.

- Wu CT, Inwards CY, O'Laughlin S, Rock MG, Beabout JW, Unni KK: Chondromyxoid fibroma of bone: a clinicopathologic review of 278 cases. Hum Pathol 29 (5): $438-446,1998$.

- $\quad$ Schajowicz F, Gallardo H :Chondromyxoid fibroma (fibromyxoid chondroma) of bone. A clinico-pathological study of thirty-two cases. J Bone Joint Surg. 53B (2): 198 - 216, 1971.

- Sharma H.Jane M J, Reid R: Chondromyxoid fibroma of the foot and ankle: 40 years' Scottish bone tumour registry experience. Int Orthop. 30(3): 205 - 209, 2006.

- $\quad$ O'Connor PJ, Gibbon WW, Hardy G, Butt WP: Chondromyxoid fibroma of the foot. Skeletal Radiol. 25: 143 - 148, 1996.

- Wang BY, Eisler J, Springfield D, Klein MJ: Intraosseous Epidermoid Inclusion Cyst in a Great Toe. A Case Report and Review of the Literature. Arch Pathol Lab Med. 27 (7): 298 - 300, 2003.

- $\quad$ Scaglietti O, Stringa G: Myxoma of bone in childhood. J Bone Joint Surg [Am]. 43-A: 67 - 80, 1961.

- $\quad$ Gherlinzoni F, Rock M, Picci P: Chondromyxoid fibroma: The experience at the instituto ortopedico Rizzoli. J Bone Joint Surg [Am]. 63-A: $198-204,1993$.
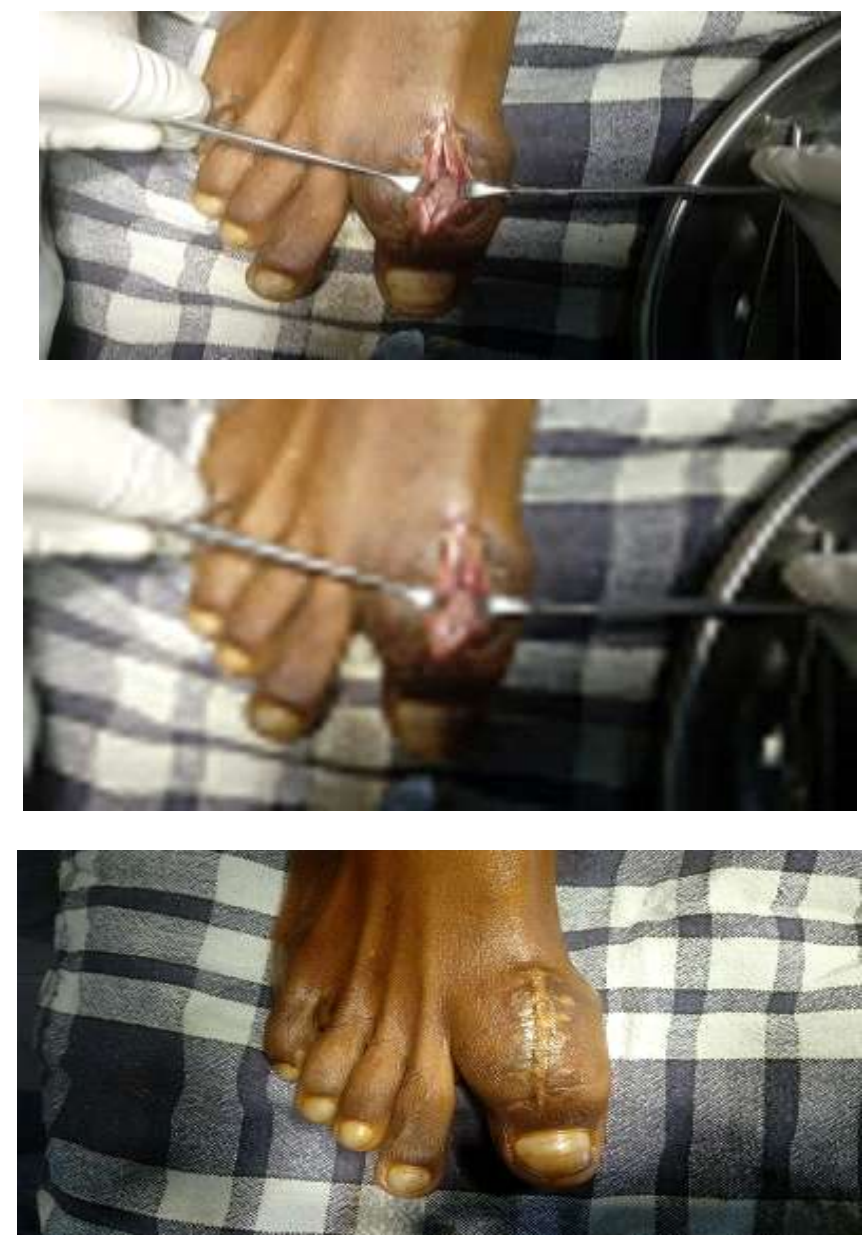

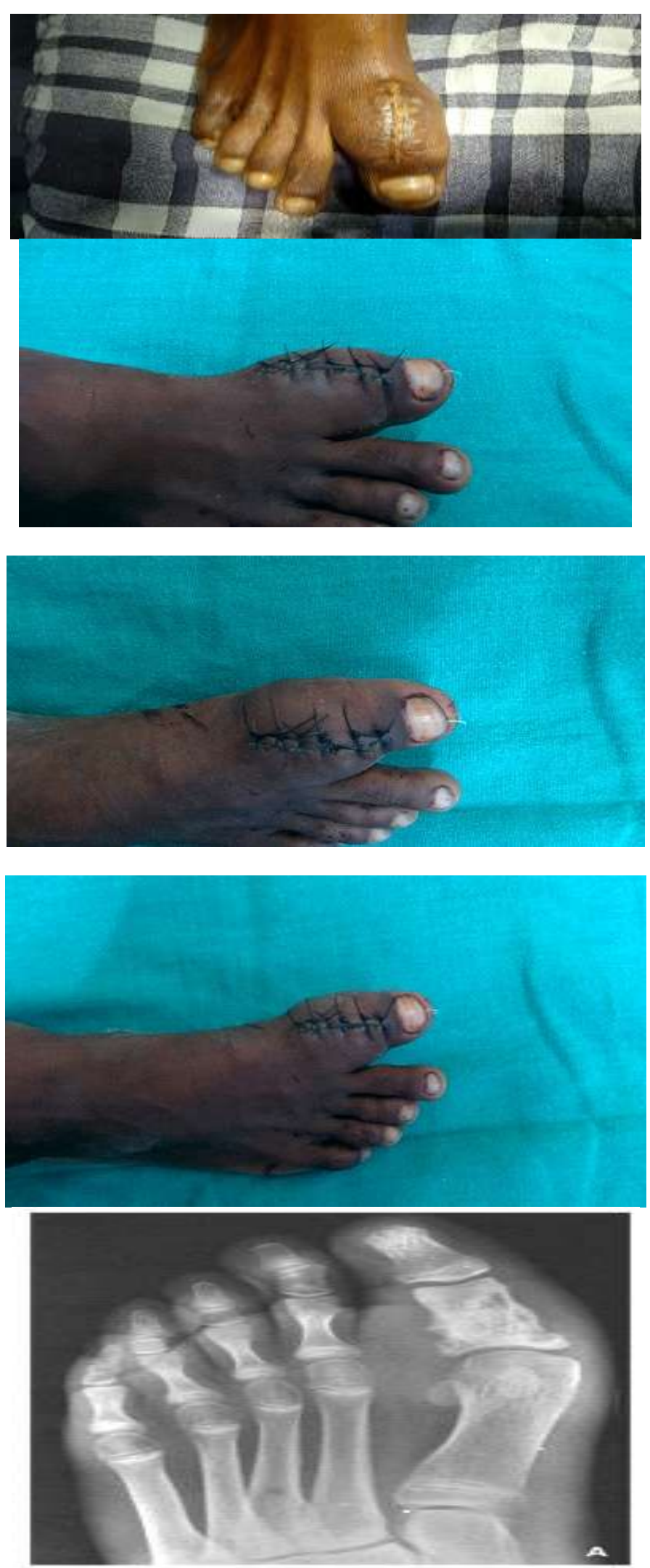

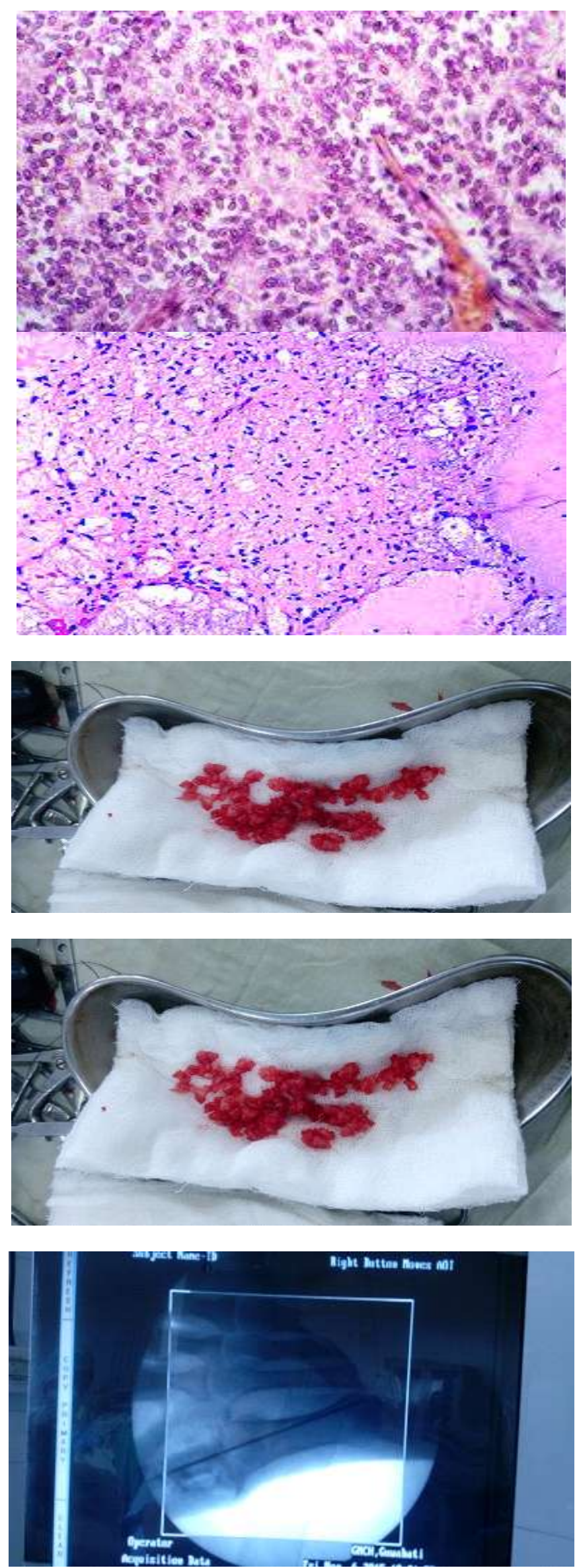

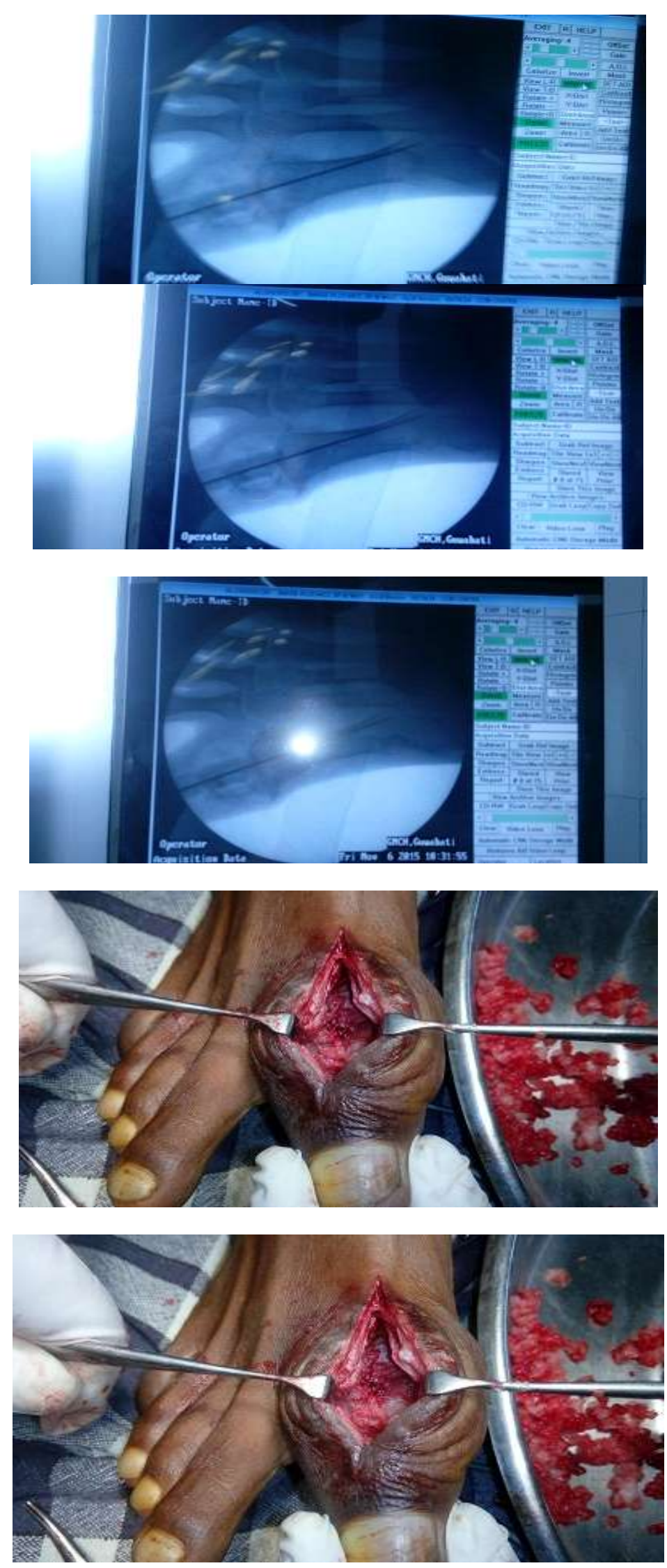

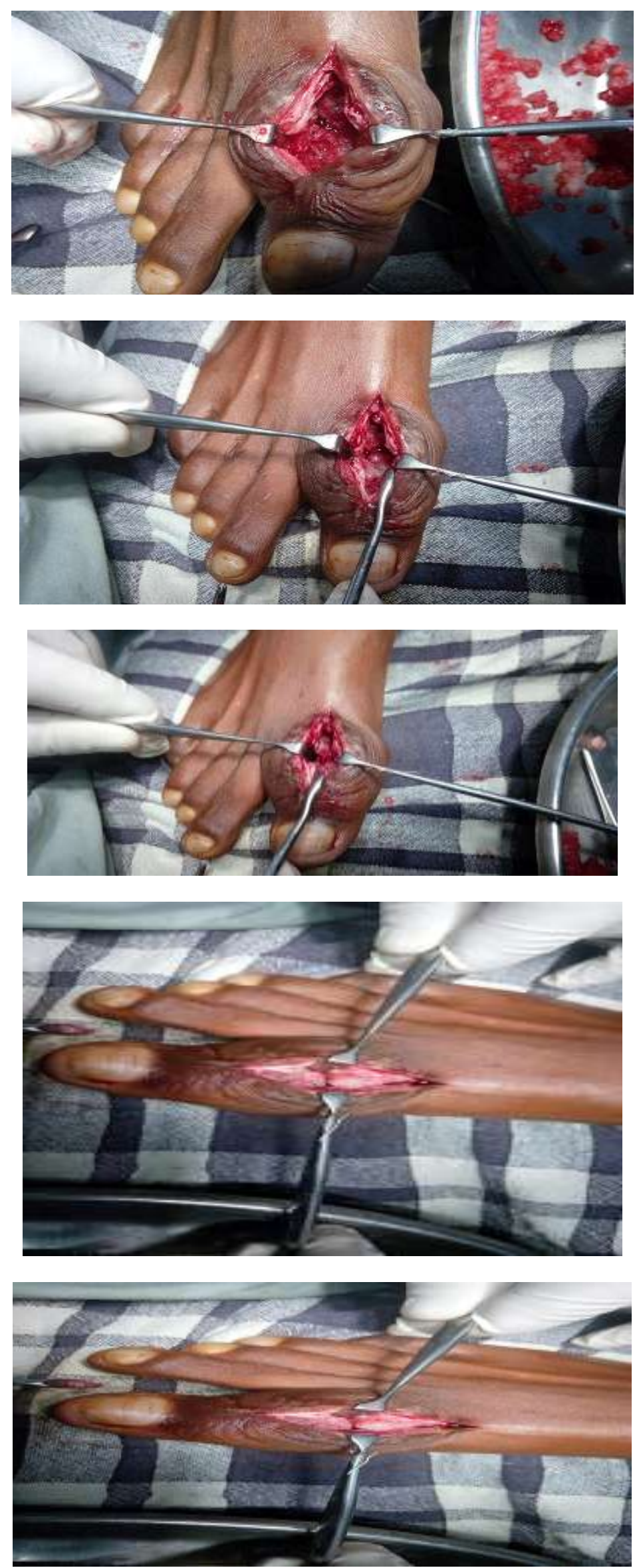